\title{
Kerf variation analysing for abrasive water jet cutting of a steel square part
}

\author{
Adrian-Paul Basarman* and Mircea Lobonțiu \\ Technical University Cluj Napoca, North University Center Baia Mare, Dr. Victor Babeș Street 62A, \\ 430083 Baia Mare, Romania
}

\begin{abstract}
The abrasive water jet cutting method is a modern method for cutting materials. It is used for cutting different type of materials, from glass, rocks, and even metals like titanium. This method has a reached a high level of usability in the nowadays modern production. In order to obtain the class of precision needed for different requirements in production, the surface quality, the kerf aspect, the shape and respectively the form of the obtained part have to be researched and analyzed. This paper presents the results obtained after cutting one square shaped part, made of S355 material. This paper presents the study regarding both the inside and the outside of the cut, the kerf width, the aspect of the taper and the profile deviation.
\end{abstract}

\section{Introduction}

The water jet is a modern method for cutting materials and there is no relevant literature for calculation of the stock left for machining for metallic parts, so there is a need of some research in order to have a more accurate view regarding this matter. This paper presents a continuation of a study started with two steel pieces made from 1C45 cutted using the same principles $[1,2]$. The present study was made on a S355 material. Researches in this field, regarding the water jet, have been made, by international authors like Fowler [3], studying the of milling the surface using the abrasive water jet technology, Hloch et. al. [4] and Valíček et.al. [5] which researched the way of turning materials using the same technology and recent studies regarding the surface roughness for steel parts cutted with AWJ was made by RavaiNagy et.al.[6] and recent studies by Hergheleghiu et. al. [7] on aluminium alloy, Filip et. al [8] on machinability and Medan et.al. [9] for parameters influence.

\section{Experimental Setup}

\subsection{Preparation for experiments}

The experiments were conducted using an abrasive water jet (AWJ) cutting machine Bystronic ByJet Pro L - as presented in Fig 1.

*Corresponding author: adrian.basarman@gmail.com 
The method of cutting materials using water, which has in it's consistency abrasive particles is a new and very different technology compared to the more commonly used conventional technology in which, in order to pierce or cut the material, a tool is needed. In this case, the tool takes contact with the surface, but using the AWJ technology, that doesn't happen anymore, so no more tools that wear out, but the parts that restrain and guide the abrasive water jet are the ones that take the extreme pressure and in the end break down.

a)
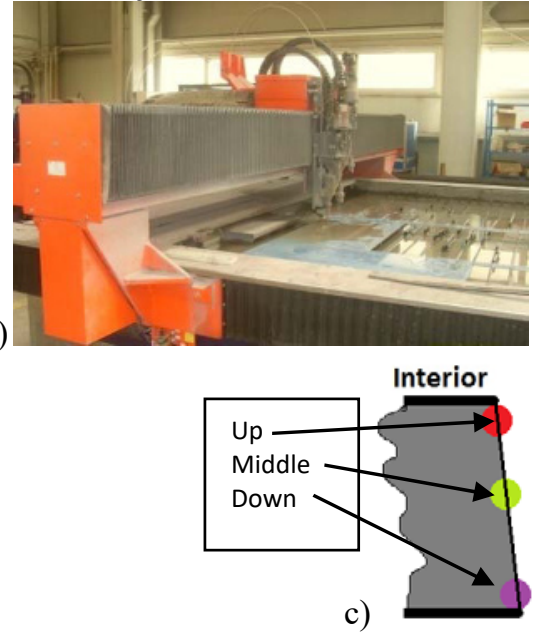

b)

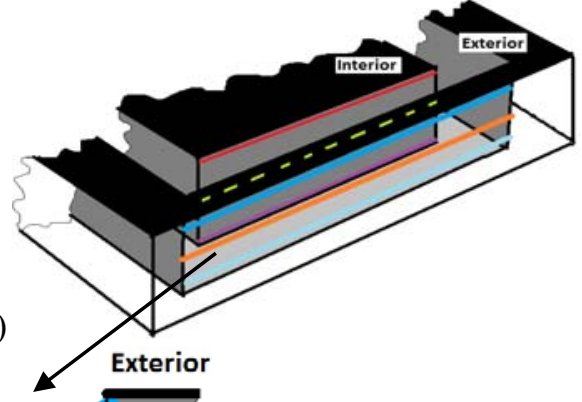

Fig. 1. a) Bystronic ByJet Pro L, b) the general aspect of the AWJ cut and the way of measuring, c)detail regarding the way of measuring the surface after cutting.

In order to take notice of how the surface has modified after cutting, we had to analyse both, the interior and the exterior of the kerf, as presented in Fig. 1b) and c). By measuring the kerf width, the values obtained can be used in order to determine the stock left for machining, needed in order to have a more precise cut and a more precise resulted surface.

These experiments were conducted on a S355 material plate, of $30 \mathrm{~mm}$ thickness. The experiment was made by cutting a 50x50 mm square part in a 70x70 square part, in order to study both the inside and outside of the cutting area.

From the list of cutting regimes offered by the machine, regarding the speed of cut, the parameters selected are presented in Table 1.

Table 1. The parameters used for the cutting regime

\begin{tabular}{|c|c|}
\hline Parameters & Value selected \\
\hline Breakthrough time & $19 \mathrm{~s}$ \\
\hline Breakthrough pressure & $3600 \mathrm{bar}$ \\
\hline Abrasive material used & $\begin{array}{c}\text { GMA Garnet } 80 \mathrm{Mesh} \\
(300-150 \mathrm{micron})\end{array}$ \\
\hline Quantity of abrasive material & $342 \mathrm{~g} / \mathrm{min}$ \\
\hline Cutting pressure & $3600 \mathrm{bar}$ \\
\hline Cutting speed & $57 \mathrm{~mm} / \mathrm{min}$ \\
\hline Interior sapphire nozzle & $0,28 \mathrm{~mm}$ \\
\hline Exterior nozzle & $0,8 \mathrm{~mm}$ \\
\hline
\end{tabular}

\subsection{Conducting the experiments}

The first step for cutting the part was using the machine's clamping system to hold the base plate in place. After this step, the program of cut was loaded in the software of the machine and after that was selecting the regime of cutting, presented in Table 1.

After this, the part is being cut and the result is presented in Fig. 2. 


\subsection{Measuring the profile deviations}

After cutting the steel part, for both parts resulted, as one can observe in Fig 2, every of the surfaces were measured separately one after another, but analysed one with each other, both for the interior and for the exterior of the cut.

Because it's a square part, it will have four exterior surfaces (E1-4) and four interior surfaces (I1-4) which were analysed together (example- exterior E1 with interior I1).

To determine the exact aspect of the surfaces, the surface was divided in three rows, as presented in Fig. 1b) and c) and using a 3D measuring arm, they were taken a number of 10 measurements on each row, 30 points per surface. Those values were set to be measured from the ideal path of cut which is exactly the theoretically path for the AWJ cutting.

Table 2. Values measured on every surface on the steel square part cutted using AWJ.

\begin{tabular}{|c|c|c|c|c|c|c|c|c|c|c|c|}
\hline $\begin{array}{l}\text { Areal } \\
\text { Part }\end{array}$ & Row & $M 1$ & $M 2$ & M3 & M4 & $M 5$ & M6 & $M 7$ & $M 8$ & $M 9$ & $M 10$ \\
\hline \multirow{3}{*}{ I/Int } & $U p$ & 0.907 & 0.857 & 0.874 & 0.868 & 0.897 & 0.899 & 0.874 & 0.876 & 0.869 & 0.884 \\
\hline & Mid. & 0.729 & 0.686 & 0.673 & 0.676 & 0.741 & 0.731 & 0.681 & 0.673 & 0.685 & 0.718 \\
\hline & Down & 0.518 & 0.528 & 0.494 & 0.513 & 0.581 & 0.547 & 0.517 & 0.487 & 0.484 & 0.554 \\
\hline \multirow{3}{*}{ I/Ext } & $\mathrm{Up}$ & -0.021 & -0.008 & -0.008 & -0.016 & -0.041 & -0.014 & -0.003 & 0.001 & -0.004 & -0.032 \\
\hline & Mid. & -0.132 & -0.054 & -0.058 & -0.075 & -0.153 & -0.130 & -0.052 & -0.061 & -0.060 & -0.149 \\
\hline & Down & -0.161 & -0.104 & -0.120 & -0.129 & -0.274 & -0.192 & -0.128 & -0.140 & -0.147 & -0.235 \\
\hline \multirow{3}{*}{ II/Int } & $\mathrm{Up}$ & 0.898 & 0.877 & 0.878 & 0.882 & 0.885 & 0.886 & 0.886 & 0.897 & 0.895 & 0.915 \\
\hline & Mid. & 1.043 & 0.964 & 0.966 & 0.968 & 0.974 & 0.979 & 0.969 & 0.970 & 0.980 & 1.061 \\
\hline & Down & 1.143 & 1.028 & 0.997 & 1.006 & 1.038 & 1.025 & 0.951 & 1.009 & 1.016 & 1.101 \\
\hline \multirow{3}{*}{ II/Ext } & $\mathrm{Up}$ & -0.059 & -0.026 & -0.012 & 0.149 & 0.100 & 0.028 & -0.040 & -0.025 & -0.058 & -0.078 \\
\hline & Mid. & 0.047 & 0.131 & 0.141 & 0.139 & 0.160 & 0.151 & 0.153 & 0.132 & 0.126 & 0.113 \\
\hline & Down & 0.236 & 0.311 & 0.392 & 0.301 & 0.321 & 0.318 & 0.322 & 0.360 & 0.340 & 0.335 \\
\hline \multirow{3}{*}{ III/Int } & $\mathrm{Up}$ & 0.935 & 0.915 & 0.902 & 0.907 & 0.899 & 0.893 & 0.887 & 0.880 & 0.872 & 0.882 \\
\hline & Mid. & 1.042 & 0.949 & 0.940 & 0.946 & 0.925 & 0.933 & 0.922 & 0.929 & 0.916 & 0.990 \\
\hline & Down & 1.008 & 0.887 & 1.014 & 0.939 & 0.964 & 0.957 & 1.048 & 0.944 & 0.968 & 1.081 \\
\hline \multirow{3}{*}{ III/Ext } & $\mathrm{Up}$ & -0.014 & 0.010 & 0.043 & -0.009 & -0.006 & 0.014 & 0.006 & -0.029 & -0.013 & -0.046 \\
\hline & Mid. & 0.126 & 0.148 & 0.141 & 0.161 & 0.183 & 0.165 & 0.139 & 0.114 & 0.121 & 0.062 \\
\hline & Down & 0.347 & 0.297 & 0.217 & 0.236 & 0.318 & 0.298 & 0.149 & 0.320 & 0.271 & 0.223 \\
\hline \multirow{3}{*}{ IV/Int } & $\mathrm{Up}$ & 0.858 & 0.821 & 0.823 & 0.834 & 0.835 & 0.843 & 0.847 & 0.862 & 0.894 & 0.921 \\
\hline & Mid. & 0.714 & 0.657 & 0.647 & 0.641 & 0.650 & 0.656 & 0.673 & 0.678 & 0.702 & 0.790 \\
\hline & Down & 0.537 & 0.418 & 0.398 & 0.443 & 0.368 & 0.461 & 0.384 & 0.472 & 0.512 & 0.455 \\
\hline \multirow{3}{*}{ IV/Ext } & $\mathrm{Up}$ & -0.114 & -0.107 & -0.100 & -0.026 & -0.071 & -0.067 & -0.056 & -0.048 & -0.027 & -0.024 \\
\hline & Mid. & -0.206 & -0.168 & -0.154 & -0.135 & -0.125 & -0.138 & -0.133 & -0.106 & -0.078 & -0.122 \\
\hline & Down & -0.345 & -0.313 & -0.271 & -0.261 & -0.246 & -0.218 & -0.221 & -0.220 & -0.126 & -0.240 \\
\hline
\end{tabular}

a)

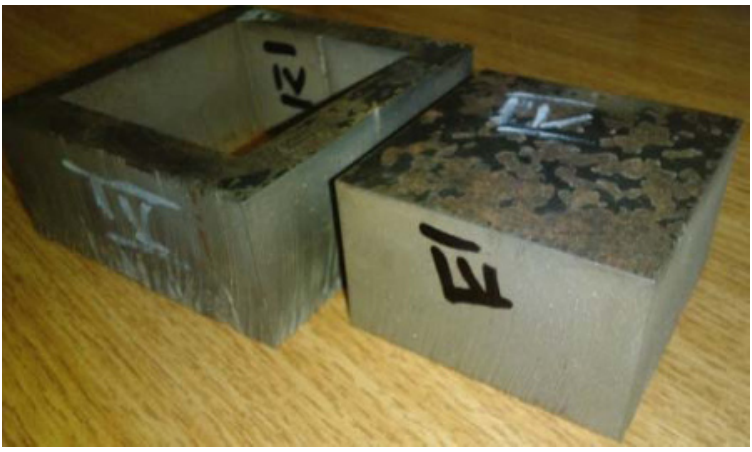

Fig. 2. The part cutted using AWJ. 


\section{Analysing the results}

After measuring every surface, the values were calculated making reference to an ideal path of cut. The results in table 2 position the measurements at some distance from the ideal path. Both, the interior or the exterior measurements, can be on same side of the path in some cases, or some of the values resulted, were with minus, positioning the result on the other side of the ideal path.

Regarding the kerf width, the values from each side of the ideal path were summed together, to form the resulted measurement of the kerf width and the values are presented in the Table 3.

This values are correspondent directly proportional with the kerf width. After analysing the values, one can observe that the smallest kerf width from all the surfaces analysed is 0,590 $\mathrm{mm}$ and the biggest kerf width was $0,996 \mathrm{~mm}$.

\section{Analysing the aspect of the surface}

The principles of cutting were the same all around the square part, and in that case, the values obtained should be almost the same, so in this care we will only present two cases:

-first one - when the cutting head moved longitudinally

-second one- when the cutting head moved transversally.

Table 3. The kerf width on every surface.

\begin{tabular}{|l|l|l|l|l|l|l|l|l|l|r|}
\hline $\begin{array}{l}\text { Area/ } \\
\text { Row }\end{array}$ & M 1 & M 2 & M 3 & M 4 & M 5 & M 6 & M 7 & M 8 & M 9 & M 10 \\
\hline I/Up & 0.928 & 0.865 & 0.882 & 0.884 & 0.938 & 0.913 & 0.877 & 0.875 & 0.873 & 0.916 \\
\hline I/Mid. & 0.861 & 0.740 & 0.731 & 0.751 & 0.894 & 0.861 & 0.733 & 0.734 & 0.745 & 0.867 \\
\hline I/Down & 0.679 & 0.632 & 0.614 & 0.642 & 0.855 & 0.739 & 0.645 & 0.627 & 0.631 & 0.789 \\
\hline II/Up & 0.957 & 0.903 & 0.890 & 0.733 & 0.785 & 0.858 & 0.926 & 0.922 & 0.953 & 0.993 \\
\hline II/Mid. & 0.996 & 0.833 & 0.825 & 0.829 & 0.814 & 0.828 & 0.816 & 0.838 & 0.854 & 0.948 \\
\hline II/Down & 0.907 & 0.717 & 0.605 & 0.705 & 0.717 & 0.707 & 0.629 & 0.649 & 0.676 & 0.766 \\
\hline III/Up & 0.949 & 0.905 & 0.859 & 0.916 & 0.905 & 0.879 & 0.881 & 0.909 & 0.885 & 0.928 \\
\hline III/Mid. & 0.916 & 0.801 & 0.799 & 0.785 & 0.742 & 0.768 & 0.783 & 0.815 & 0.795 & 0.928 \\
\hline III/Down & 0.661 & 0.590 & 0.797 & 0.703 & 0.646 & 0.659 & 0.899 & 0.624 & 0.697 & 0.858 \\
\hline IV/Up & 0.972 & 0.928 & 0.923 & 0.860 & 0.906 & 0.910 & 0.903 & 0.910 & 0.921 & 0.945 \\
\hline IV/Mid. & 0.920 & 0.825 & 0.801 & 0.776 & 0.775 & 0.794 & 0.806 & 0.784 & 0.780 & 0.912 \\
\hline IV/Down & 0.882 & 0.731 & 0.669 & 0.704 & 0.614 & 0.679 & 0.605 & 0.692 & 0.638 & 0.695 \\
\hline
\end{tabular}

In Fig 3a) it can be seen the aspect of the cut, and also of the surfaces, both for the interior of the cut and also for the exterior. One can see that the surface has an irregular shape, and it presents, by observing the values in the table 2, a narrowing of the surface in the down area, and the whole surface that was cut, it's not straight, from top to bottom, it has an inclination of cut towards the exterior.

Putting the values together, it was generated the aspect of the width of cut, shown in the Fig $3 b)$.

As it can be observed in Fig 3a), the bulging aspect of the surface is accentuated in the middle and even more up in the corners and the more different is measurement 5 which is opposite to measurements 3 and 9 (counting starts from the first left vertical line). The aspect from the corners may result because of the machine error while switching the movement direction from one axis to another. On this surface, the smallest kerf width resulted here is $0,614 \mathrm{~mm}$ and the biggest kerf width is $0,938 \mathrm{~mm}$, as presented in Table 3 and Fig $3 \mathrm{~b}$ ). 

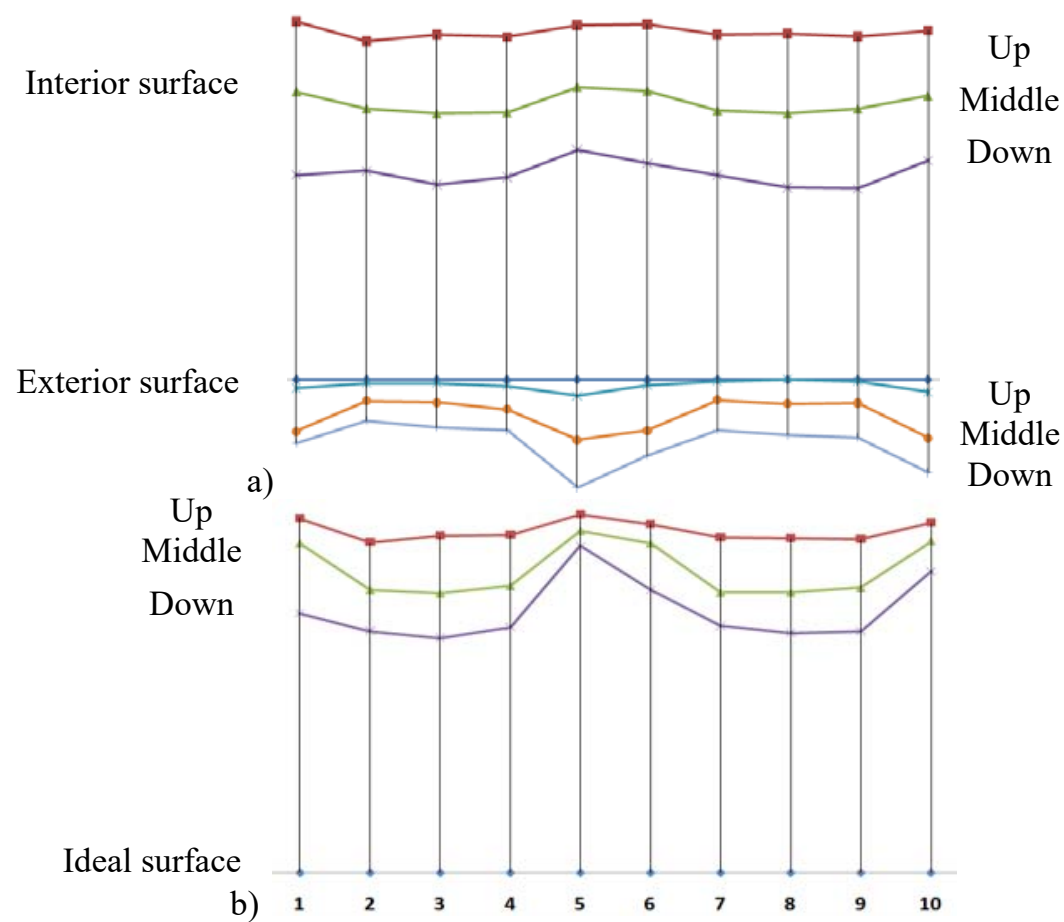

Fig. 3. a)Top view for the aspect of the surface I; b)The width of cut for surface I.

Analysing the next surface, presented in Fig 4, similar aspects can be seen, like in the ones in Fig 3, but here, some of the exterior, and also some of the interior lines, intersect.

As one can see, in Fig 4, as presented, it can be observed a little difference from the surface I. The surfaces are a bit more straight but presents also a V shaped taper, and in this case, the sliding is towards the interior, opposite to the first surface. In Fig 5 one can observe the kerf width for the second surface.

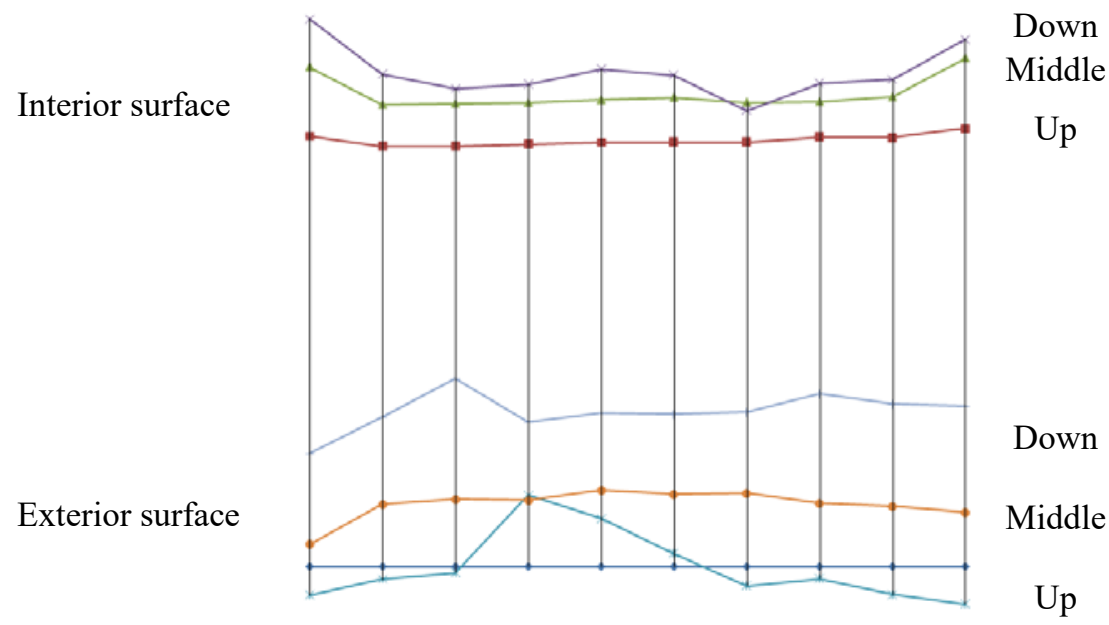

Fig. 4. Top view for the aspect of surface II. 


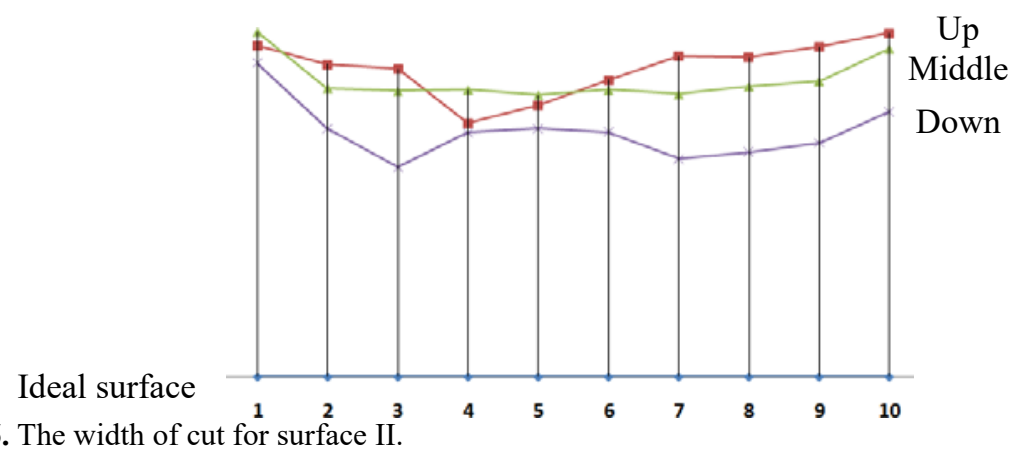

Fig. 5. The width of cut for surface II.

As can be seen in Fig 5, the surface a bulging aspect in the middle and more up in the corners because the water jet kicked back, the surface has irregular shape, and the lines intersect. The smallest kerf width resulted is $0,605 \mathrm{~mm}$ and the biggest one is $0,996 \mathrm{~mm}$. Rezults that the error of the machine is the problem, while switching direction. Analyzing the results, both, the smallest kerf width and the biggest kerf width are very similar.

\section{Conclusions}

1)The surface aspect has an inclination because of the error of the machine.

2)The maximum stock needed to be left for machining with abrasive water jet (AWJ) is $0,996 \mathrm{~mm}$ for a $30 \mathrm{~mm}$ thickness steel $\mathrm{S} 355$ part, cutted at a speed of $57 \mathrm{~mm} / \mathrm{min}$.

3)The surface cut using AWJ technology presents a V-shape tapper.

\section{References}

A.P. Basarman, M. Lobonțiu, Nonconventional Technologies Review 20, 2 (2016)

A.P. Basarman, D. Damjanovic, M. Lobonțiu, N. Medan, TEAM 2016 Proceedings (2016)

G. Fowler, Abrasive water jet: controlled depth milling of titanium alloys, PhD. Thesis, University of Nottingham (2003)

S. Hloch, J. Hlaváček, K. Vasilko, J. Cárach, et al, METABK 53 (4), 537-540 (2014)

J. Valíček, M. Harničárová, I. Hlavatý, R. Grznárik, M. Kušnerová, Z. Hutyrová, A. Panda, Materialwissen-schaft und Werkstoff-technik, 46, 4-5 (2015)

S. Ravai-Nagy, N. Medan, Hidraulica 4, 2-17 (2016)

E.Herghelegiu, M.C. Radu, C. Schnakovszky, C.N. Tampu., CoSME'16 MATEC Web of Conferences 94, 03007 (2017)

A.C. Filip, M.A. Vasiloni, L. A. Mihail, CoSME'16 MATEC Web of Conferences 94, 03003, (2017)

N. Medan, M. Banica, IManEE2016, IOP Conf. Series: Materials Science and Engineering 161, 012016 (2016) 